\title{
Analisis Nilai Hambur Balik Sedimen Permukaan Dasar Perairan Menggunakan Data Multibeam Echosounder EM302
}

\author{
Kamila Akbar, Danar Guruh Pratomo, dan Khomsin \\ Departemen Teknik Geomatika, Fakultas Teknik Sipil dan Lingkungan, Institut Teknologi Sepuluh \\ Nopember (ITS) \\ e-mail: kamila.akbar13@mhs.geodesy.its.ac.id,guruh@geodesy.its.ac.id, khomsin@geodesi.its.ac.id
}

\begin{abstract}
Abstrak-Multibeam echosounder merupakan instrumen akustik untuk pemetaan dasar perairan yang menghasilkan data kedalaman dan data nilai hambur balik (backscatter). Analisis terhadap nilai hambur balik memungkinkan dalam menentukan jenis, struktur dan sebaran sedimen dasar perairan. Intensitas hambur balik yang kuat menunjukkan jenis sedimen yang keras (gravel, boulder) dan intensitas hambur balik yang lemah menunjukkan permukaan yang halus (mud, silt). Metode yang digunakan dalam analisis nilai hambur balik yaitu metode Angular Response Curve, dimana hubungan antara nilai intensitas hambur balik dan respon sudut pancaran menghasilkan mosaik backscatter yang berbanding terbalik dengan resolusi spasial yang diberikan. Penelitian ini menggunakan data hasil survei Indonesia Exploration 2010, dengan instrumen MBES Kongsberg EM302 di perairan Sangihe Talaud, Sulawesi Utara. Pemrosesan raw data dilakukan dengan perangkat lunak SwathEd yang menghasilkan peta batimetri dan mosaik hambur balik. Dari mosaik hambur balik, didapatkan rentang nilai hambur balik -9 dB sampai dengan $-67 \mathrm{~dB}$. Dilakukan reklasifikasi, didapat 5 kelas jenis sedimen, yaitu tanah liat (clay), lumpur (mud), pasir (silt), kerikil (gravel), dan batu besar (boulder).
\end{abstract}

Kata Kunci-Multibeam Echosounder, Nilai Hambur Balik, Sedimen, Batimetri.

\section{PENDAHULUAN}

$\mathrm{M}$ ULTIBEAM echosounder (MBES) merupakan instrumen akustik yang digunakan untuk pemetaan dasar perairan dengan prinsip menghasilkan sinyal akustik pendek atau ping menuju dasar perairan dan menangkap sinyal yang terpantul dari dasar perairan. Selang waktu antara penyebaran sinyal akustik dan kembalinya sinyal adalah nilai kedalaman berdasarkan selang waktu tempuh gelombang akustik pergipulang. Nilai kedalaman tersebut digunakan untuk mengetahui keberadaan benda-benda di bawah perairan [1].

Selain data kedalaman, data lain yang didapat dari instrumen MBES yaitu nilai hambur balik (backscatter) dari sinyal akustik yang dipantulkan oleh permukaan dasar perairan. Backscatter adalah intensitas sinyal akustik yang dipantulkan oleh dasar perairan menggunakan fungsi respon sudut pancaran (angular response), hasil yang didapat berupa kurva hubungan antara nilai intensitas hambur balik dan respon sudut pancaran. Dari hubungan ini dapat ditentukan tipe sedimen dasar perairan dimana tiap tipe sedimen yang berbeda biasanya menunjukkan tingkat intensitas yang berbeda, sehingga dapat digunakan untuk mengidentifikasi tipe dan penyebaran sepasial morfologi dari sedimen dasar perairan [2].

Salah satu metode yang digunakan dalam menganalisis hubungan antara nilai intensitas hambur balik dan respon sudut pancaran yaitu metode Angular Response Curve yang dikembangkan oleh Fonseca dan Calder pada tahun 2007. Namun, keterbatasan metode ini terletak pada kemampuan instrumen MBES yang digunakan. Hasil mosaik backscatter yang dihasilkan dari pemrosesan sinyal akustik berbanding terbalik dengan resolusi spasial yang diberikan. Dapat dikatakan ketika analisis mengenai respon sudut (angular curve) menghasilkan nilai yang tinggi, maka resolusi spasial yang dihasilkan akan rendah [3].

Pada penelitian ini dilakukan analisis terhadap respon sudut dari sinyal akustik MBES yang kembali akan menghasilkan informasi mengenai struktur dan kekerasan (roughness) sedimen dasar perairan, yang digunakan untuk melakukan klasifikasi tipe sedimen dasar perairan.

\section{URAIAN PENELITIAN}

\section{A. Data dan Lokasi Penelitian}

Data yang digunakan pada penelitian ini adalah Raw data leg 2 Multibeam Echosounder EM302 pada wahana kapal survei RV Okeanos Explorer yang diakuisisi pada tanggal 23 Juni - 25 Juni 2010 selama Ekspedisi Indonesia Exploration 2010 berformat *.all. Data lain yaitu data Pasang Surut Stasiun Pasut Pelabuhan Bitung Juni-Juli 2010 dan Data Sound Velocity Profiler wahana R/V Okeanos Exploration selama akuisisi MBES. Selanjutnya data-data tersebut diolah dan digabung menjadi format (*.merged) dan format (*.ss) untuk dianalisis lebih lanjut.

Lokasi Penelitian ini berada pada perairan sebelah barat Kepulauan Sangihe, Provinsi Sulawesi Utara, yang berada pada koordinat $2^{\circ} 01^{\prime} \mathrm{LU}-6^{\circ} 24^{\prime} \mathrm{LU}$ dan $124^{\circ} 45^{\prime} \mathrm{BT}-128^{\circ}$ BT . Peralatan yang digunakan dalam penelitian ini adalah laptop dengan dual OS Windows 7 dan Ubuntu 14.04. Perangkat lunak SwathED pengolah raw data MBES yang dikembangkan oleh Prof. John Hughes Clarke, UNH Canada. 
Perangkat lunak MB-System untuk pengolahan backscatter. Perangkat lunak ArcMap 10.3 dan perangkat lunak pengolah DTM.

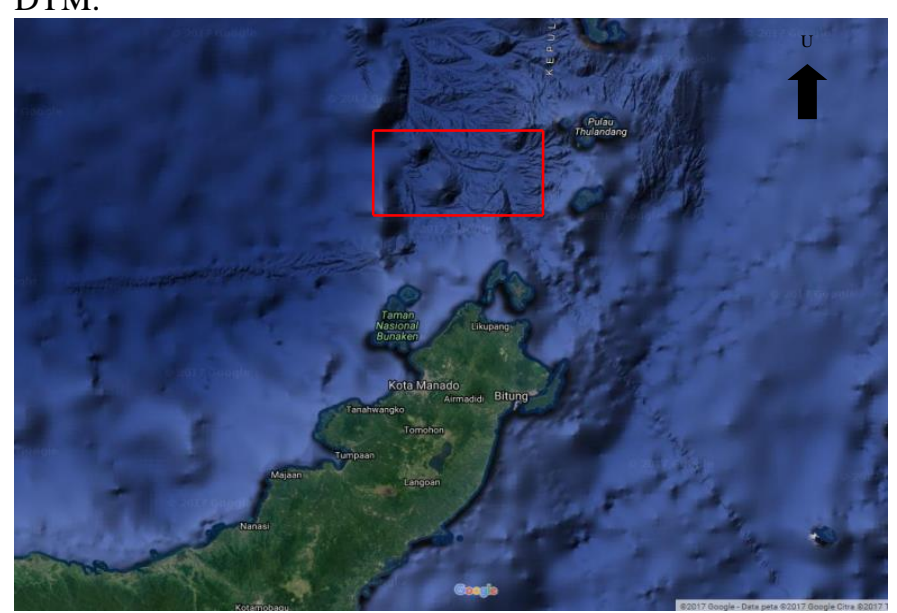

Gambar 1. Lokasi Penelitian (Google Earth, 2017)

\section{B. Tahap Pengolahan Data}

Berikut tahap pengolahan data pada penelitian ini :

1) Pengolahan data MBES

Tahap ini akan dipilih raw data yang akan digunakan pada penelitian ini, yaitu 0015_EX.all sampai 031_EX.all yang diakuisisi pada tanggal 23-24 Juni 2010 oleh wahana R/V Okeanos Explorer.

Selanjutnya raw data diolah melalui proses unravel, yaitu proses pengolahan raw data MBES untuk dijadikan format pengolahan pada perangkat lunak SwathED. Format raw data *.all digabung menjadi format *.merged untuk batimetri dan *.ss_dg untuk mosaik backscatter. Data pasang surut selama akuisi data MBES disesuaikan formatnya menjadi *.bin untuk dikoreksikan dengan file *.merged dengan perintah MergeTide.

Proses cleaning data MBES yang masih terdapat spike dilakukan pada pada tab swath profile dengan median filter dimana menghilangkan spike yang nilai kedalamannya berbeda jauh dengan nilai kedalaman median.

File *.merged yang sudah clean dibuat DTM dengan parameter : $5 \mathrm{~m} /$ pixel, beamwidth 1.0 , vertical exaggeration 1.0. Setelah itu file dtm berformat *.r4 diekspor ke format ESRI dengan perintah R4toESRI untuk diolah lebih lanjut.

\section{2) Pengolahan Nilai Hambur Balik}

Format backscatter *.ss_dg dikoreksi untuk menghilangkan nadir stripping, menghilangkan variasi beam pattern, dan georefencing. Dibuat mosaik backscatter dengan perintah mos2 dan berformat *.mos.

Setelah itu, file *.mos diekspor ke format ESRI dengan perintah r4toESRI menjadi format float file atau *.flt.

Selanjutnya file mosaik backscatter *.flt diolah dengan perangkat lunak ArcMap 10.3 untuk diklasifikasi jenis sedimen dari backscatter value yang didapatkan dari nilai pixel (DN=Digital Number) pada mosaik yang selanjutnya dikonversi ke 24-bit format satuan desibel (dB). Nilai desibel dan sudut pancar MBES (grazing angle) kemudian dibuat grafik untuk mendapatkan hubungan backscatter value dan jenis sedimen permukaan dasar perairan.

\section{HASIL DAN ANALISIS}

\section{A. Hasil Batimetri}

1) Digital Terrain Model

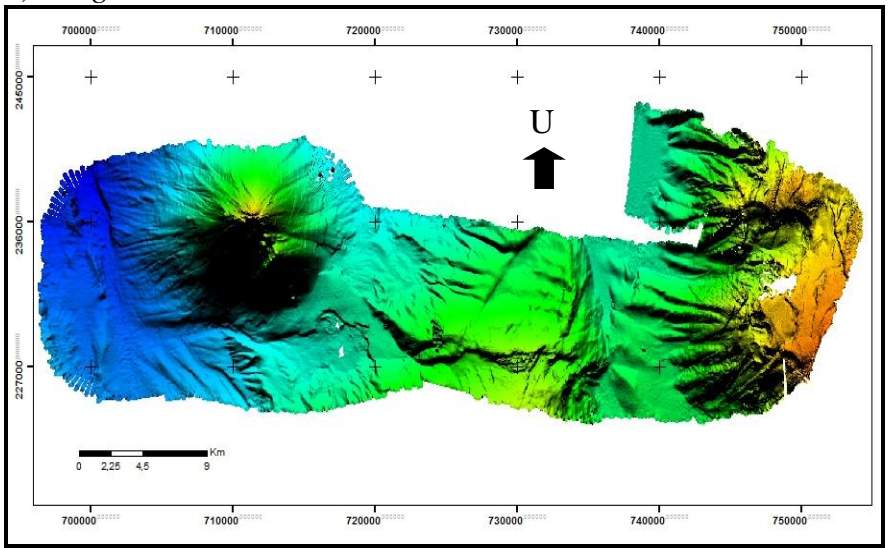

Gambar 2. DTM Area Penelitian
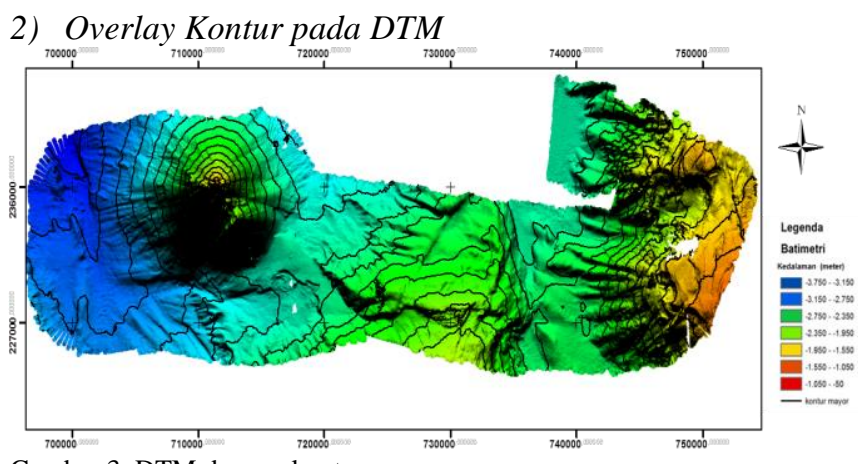

Gambar 3. DTM dengan kontur

DTM yang sudah diolah, kemudian dibuat kontur dengan interval kontur mayor $200 \mathrm{~m}$.

\section{B. Hasil Analisis Nilai Hambur Balik}

1) Mosaik nilai hambur balik (backscatter) yang terkoreksi :
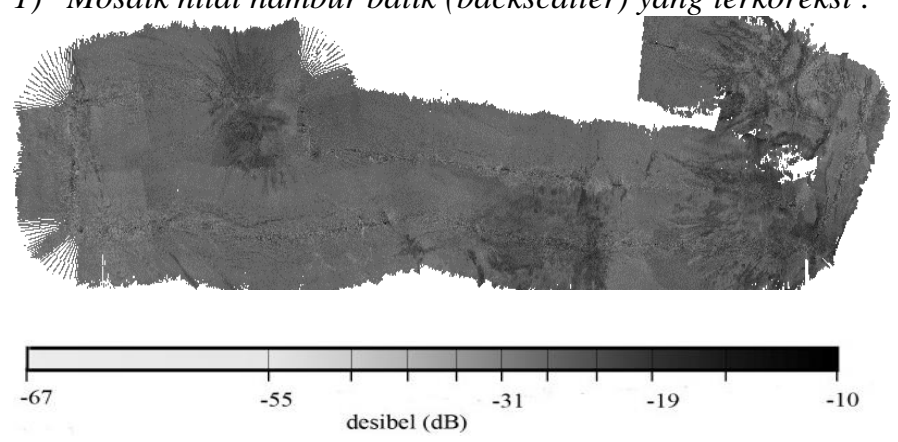

Gambar 4. Mosaik Hasil Koreksi

\section{2) Pembahasan}

Nilai hambur balik yang telah didapatkan dari hasil pemrosesan berupa Digital Number yang berasal dari tiga zona sapuan beam instrumen MBES yaitu zona nadir, zona oblique, dan zona grazing. Nilai DN dikonversikan ke Nilai desibel (dB) dengan persamaan yang dikembangkan oleh Hughes Clarke [4] :

$$
\mathrm{dB}=\frac{\mathrm{DN}-255}{2}
$$


Pada area yang tersusun oleh sedimen batuan besar (boulder) didapatkan nilai hambur balik yang sangat kuat (high intensity) sebesar 237 sampai 211 DN atau dengan menggunakan Persamaan 1 didapatkan nilai desibel antara -9 sampai -22 dB (desibel). Area yang tersusun oleh sedimen batuan kerikil (gravel) memiliki nilai hambur balik sebesar 209 sampai 187 DN atau sekitar -23 sampai -34 dB. Area yang tersusun oleh sedimen pasir (silt/sand) memiliki nilai hambur balik sebesar 185 sampai 159 DN atau sekitar -35 sampai -48 $\mathrm{dB}$. Area yang tersusun oleh sedimen lumpur ( $m$ mud) memiliki nilai hambur balik sebesar 157 sampai 137 DN atau sekitar -49 sampai $-59 \mathrm{~dB}$. Area yang tersusun oleh sedimen tanah liat (clay) memiliki nilai hambur balik yang sangat lemah (low intensity) sebesar 135 sampai 127 DN atau sekitar sekitar -60 sampai $-67 \mathrm{~dB}$.

\section{3) Grafik Angular Response Curve}

Nilai hambur balik terkoreksi yang diperoleh dari hasil ekstraksi nilai hambur balik tiap sampel jalur pemeruman selanjutnya diplot dengan sudut pantul/grazing angle untuk mengetahui hubungan jenis sedimen berdasarkan sudut pantul MBES dengan permukaan dasar perairan.

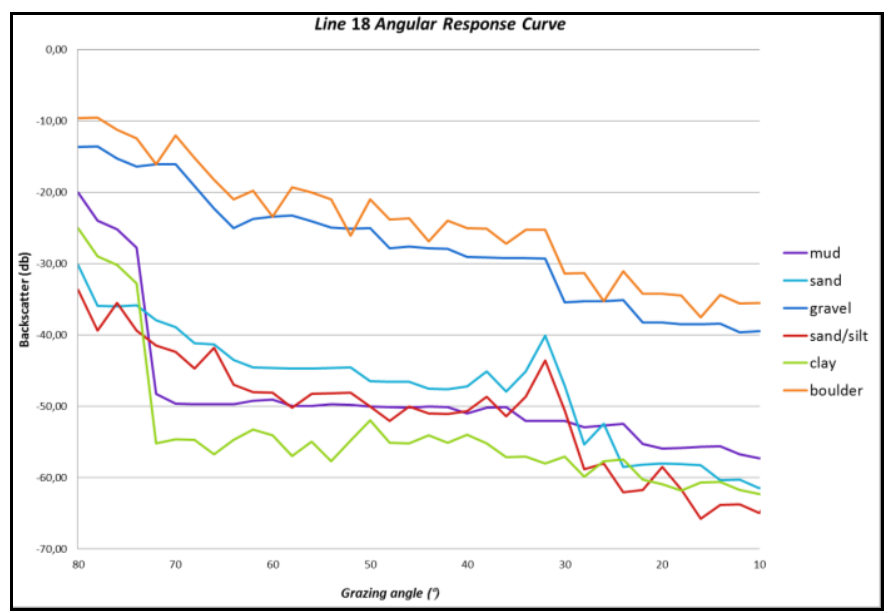

Gambar 5. Kurva ARC Line 18

Pada Gambar 5 menunjukkan kurva hubungan antara nilai hambur balik dengan grazing angle pada sampel line 18. Tiap garis yang berbeda warna pada kurva mewakili nilai hambur balik dari jenis sedimen berbeda.

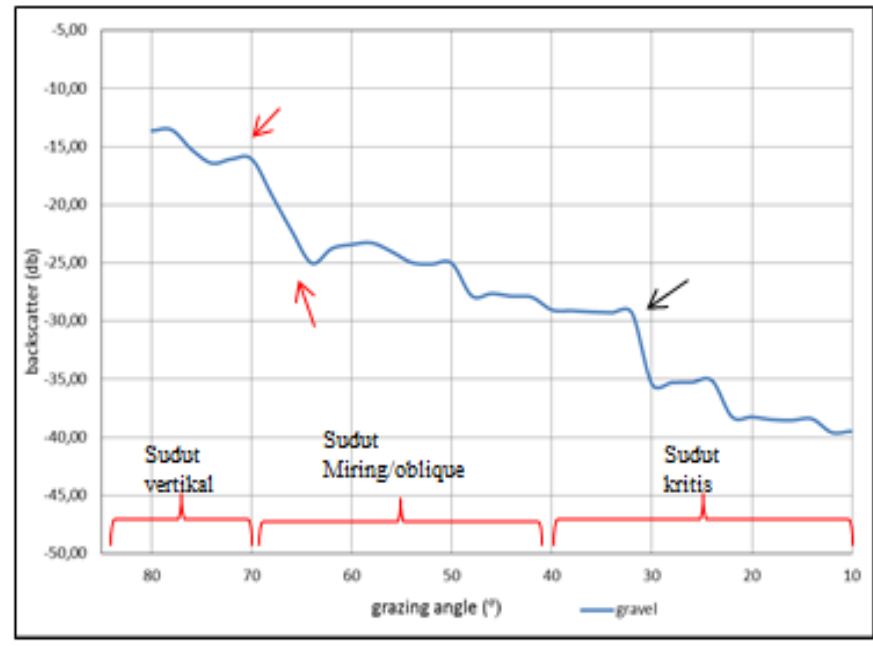

Gambar 6. Kurva ARC sedimen gravel

Pada jenis sedimen gravel (kerikil) respon sudut nilai hambur balik ditunjukkan oleh Gambar 6. Respon sudut nilai hambur balik pada nadir sangat kuat disebabkan oleh kedataran permukaan pada sedimen kerikil yang memungkinkan untuk merefleksikan sinyal akustik dengan sedikit menghamburkan sinyal akustik. Namun, pada saat grazing angle bernilai $70^{\circ}-60^{\circ}$ (ditunjukkan oleh panah merah) terjadi penurunan nilai hambur balik yang signifikan, hal ini disebabkan oleh kemiringan/oblique sudut pantul sinyal akustik yang diterima oleh transduser. Begitu juga pada saat sudut kritis $30^{\circ}-10^{\circ}$ (ditunjukkan panah hitam), dimana sinyal akustik direfleksikan dengan sudut yang kecil sehingga nilai hambur balik semakin melemah atau bahkan hilang.

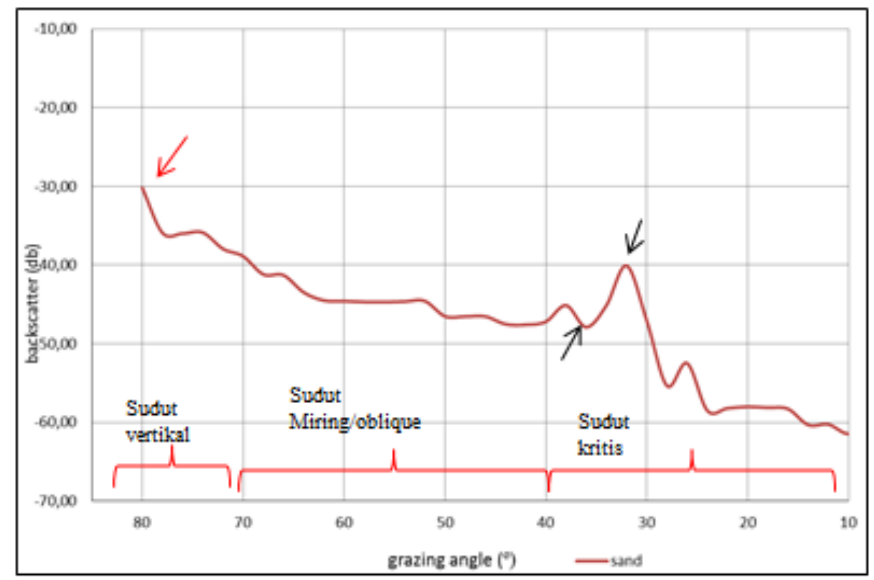

Gambar 7. Kurva ARC Sedimen Sand

Sama seperti angular response curve pada jenis sedimen gravel, angular response curve pada jenis sedimen sand yang ditunjukkan pada Gambar 7 nilai hambur balik pada nadir sangat kuat, dan mengalami penurunan pada area sudut miring atau grazing angle $70^{\circ}-40^{\circ}$. Namun pada saat sudut kritis, nilai hambur balik mengalami kenaikan dan membentuk puncak (ditunjukkan panah hitam) kurva pada sekitar grazing angle $30^{\circ}$. 


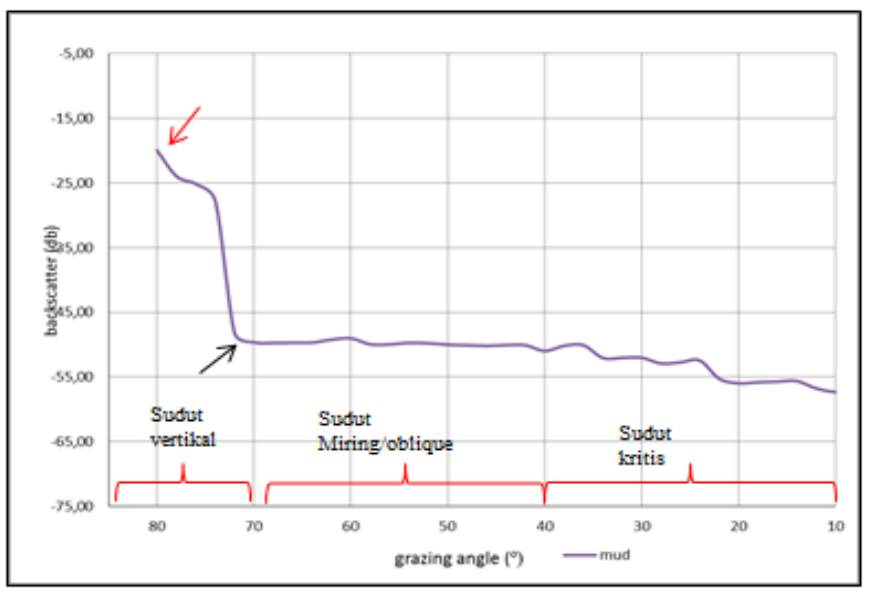

Gambar 8, Kurva ARC sedimen mud

Gambar 8 menunjukkan kurva angular response pada jenis sedimen mud. Pada sudut nadir, nilai hambur balik masih memiliki intensitas yang kuat yang didominasi oleh volume scattering, namun ketika grazing angle $70^{\circ}$ dan semakin menurun, nilai hambur balik sedimen mud semakin melemah dengan kurva yang menurun dengan halus (ditunjukkan dengan panah hitam),penurunan nilai hambur balik ini terjadi sampai dengan grazing angle $10^{\circ}$.

\section{4) Persebaran Nilai Hambur Balik}

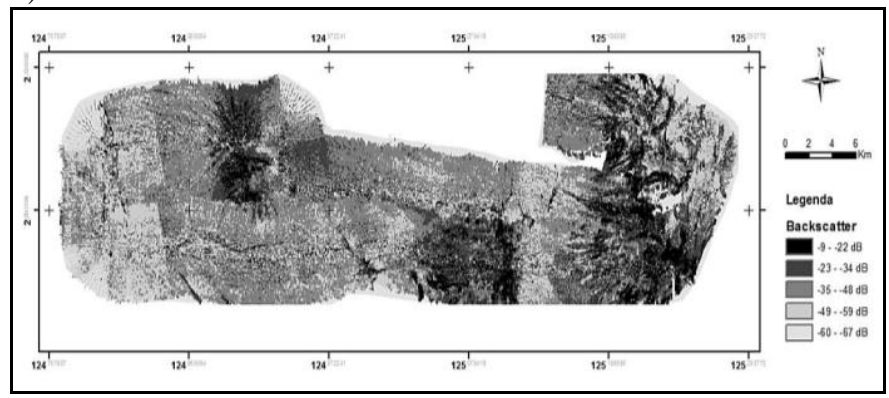

Gambar 9. Persebaran Nilai Hambur Balik

\section{5) Persebaran Jenis Sedimen berdasarkan Nilai Hambur} Balik

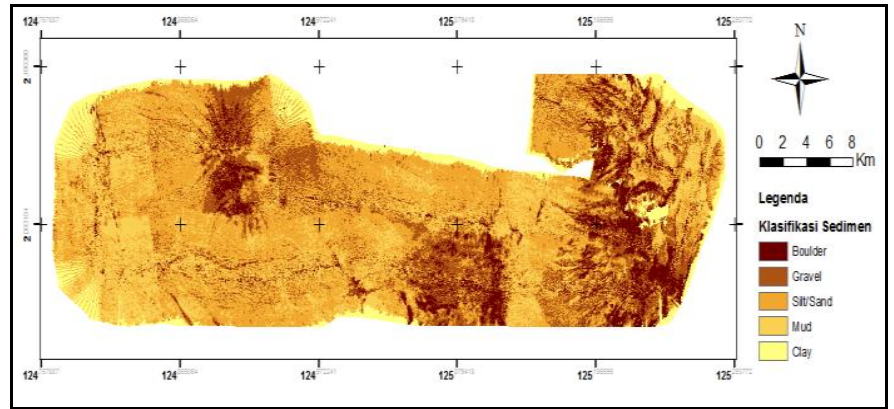

Gambar 10. Persebaran Jenis Sedimen

\section{KESIMPULAN DAN SARAN}

Kesimpulan yang dapat diambil dari penelitian tentang analisis nilai hambur balik sedimen dasar perairan menggunakan Multibeam Echosounder EM302 adalah sebagai berikut :
1. Sebaran nilai hambur balik terkoreksi pada area penelitian memiliki nilai hambur balik maksimum $-10 \mathrm{~dB}$ dan minimum $-67 \mathrm{~dB}$ dan memiliki rentang nilai $\mathrm{DN}$ sebesar $237-121 \mathrm{DN}$.

2. Hasil persebaran jenis sedimen berdasarkan analisis nilai hambur balik dengan metode Angular Response Curve, yaitu:
a. -9 sampai $-22 \mathrm{~dB}$ merupakan sedimen batuan besar (boulder)
b. -23 sampai -34 dB merupakan sedimen kerikil (gravel)
c. -35 sampai $-48 \mathrm{~dB}$ merupakan sedimen pasir (silt/sand)
d. -49 sampai $-59 \mathrm{~dB}$ merupakan sedimen lumpur ( $m u d$ )
e. -60 sampai $67 \mathrm{~dB}$ merupakan sedimen tanah liat (clay).

Saran yang dapat digunakan untuk penelitian selanjutnya mengenai nilai hambur balik instrumen multibeam echosounder yaitu sebagai berikut:

1. Penggunaan data coring atau pengambilan sampel sedimen untuk memverifikasi data jenis sedimen dari nilai hambur balik.

2. Parameter koreksi pada area nadir yang memiliki intensitas hambur balik yang tinggi, sehingga menyebabkan klasifikasi sedimen yang kurang tepat.

3. Hasil peta sebaran sedimen dapat digunakan untuk penelitian mengenai kondisi habitat dan ekosistem dasar perairan .

\section{UCAPAN TERIMA KASIH}

Penulis mengucapkan terima kasih kepada BPPT dan NOAA sebagai pihak penyedia data, Ocean Mapping Group UNB Canada sebagai pengembang perangkat lunak SwathEd..

\section{DAFTAR PUSTAKA}

[1] D. Y. HM Manik, "Development and Application of MB System Software for Bathymetry and Seabed Computation," J. Softw. Eng. its, 2015.

[2] S. A. Che Hasan R, Ierodiaconou D, Laurenson L, "Integrating multibeam backscatter angular response, mosaic and bathymetry data for benthic habitat mapping. PLoS One," 2014.

[3] M. L. Fonseca L, "Remote estimation of surficial seafloor properties through the application angular range analysis to multibeam sonar data," Mar. Geophys. Res., 2007.

[4] and D. E. W. Hughes Clarke, J.E., L.A. Mayer, "Shallow-water imaging multibeam sonars: A new tool for investigating seafloor processes in the coastal zone and on the continental shelf," Mar. Geophys. Res., pp. 607-629, 1996. 